\title{
ANNOTATIONS
}

\section{The Royal London Ophthalmic Hospital Reports}

The final number of the Royal London Ophthalmic Hospital Reports made its appearance in July last. It contains an epilogue and an index to Volume XX, together with a general index to volumes XII to XX, covering the years 1890-1916. The epilogue, quoted in full below, is couched in most sympathetic strain :

\section{EPILOGUE.}

"As our readers know, the Royal London Obhthalmic Hosbital Reports ceased publication with the present number. Together with the Ophthalmic Review and the Ophthalmoscope they merge into the new BRITISH JOURNAL OF OPHTHALMOLOGY, which commenced its career in January of this year. We need not, therefore, bewail their loss as an annihilation, but rather regard them as undergoing a metamorphosis and a rejuvenescence.

In bidding them farewell in their old familiar form, it is natural that we should glance back over their long and eventful history. Established in 1857, they have reached their diamond jubilee. It was a remarkably fertile period in the history of ophthalmology when the Moorfields Hospital Reports were born. Von Helmholtz, von Graefe, Donders, Bowman, and William Mackenzie were in the zenith of their activities. Only a few years had elapsed since the ophthalmoscope had been re-discovered by Helmholtz (1851), and introduced to clinical use by von Graefe and his pupils. Modern ophthalmology was born in those days, and the Reports were one of its first products. Sir William Bowman's name is indelibly associated with the dawn of the new era in England, and it appears in the first number of the new journal. For it was from the start a journal rather than a mere collection of reports of hospital cases. At that time there was no English periodical publication devoted to ophthalmology, and there was no Ophthalmological Society. Moorfields Eye Hospital, to give it its familiar and time-honoured designation, was the unique centre of British ophthalmology, and at once became the heart and soul of the new movement. Hitherto those of our surgeons who were interested in diseases of the eye had been forced to contribute their observations to the general medical journals, such as the Lancet and the Medical Press. They must have often felt that their more recondite communications on ophthalmic subjects made little appeal to the readers of these periodicals, and were buried in them and liable to be overlooked and forgotten. In such cases they had no recourse open to them but to publish in the long-established Annales d'Oculistique. The Moorfields Reports provided them with a new medium. It is true that, from the beginning, original articles appear to have been 
accepted only from those who had worked at the Hospital, but there is little evidence of disadvantage accruing from this fact. Thus we find communications in the early volumes from such men as William Mackenzie, the greatest ophthalmic clinician of preophthalmoscopic days, Sir William Bowman, George Critchett, J. W. Hulke, Sir Jonathan Hutchinson, Dr. Hughlings Jackson, T. Wharton Jones, George Lawson, Henry Power, Argyll Robertson, J. F. Streatfield, Pridgin Teale, Spencer Watson, Soelberg Wells, J. C. Wordsworth, and many others. Certainly in later days the rule was strictly observed, and the list of contributors to the twenty volumes of the Reports is one of which any hospital may well feel proud. It is unnecessary to enumerate other names of world-wide renown, but it should not be forgotten that Edward Nettleship published much of his finest work in these pages. The widespread influence of the Moorfields teaching is exemplified by papers which bear the names of J. W. Barrett, of Melbourne, and of Americans such as Webster Fox and Casey Wood.

With the third volume, in 1860, the Reports assumed still more the character of a journal by the addition of a "periscope" of current ophthalmic literature. This feature was discontinued after vol. ix (1877).

It has often been held up as a reproach to British ophthalmologists that they neglect the more purely scientific aspects of their subject. It finds little support from the contents of these Reports. Valuable papers on applied optics have been written by G. Rainy, W. Charnley, A. H. S. Hallidie, and others. Pathological anatomy has always been a conspicuous feature, and, indeed, the Reports owe much of their success to the energy and enthusiasm of successive Curators-C. Bader, E. Nettleship, W. A. Brailey, W. J. Milles, J. B. Lawford, E. Treacher Collins, C. Devereux Marshall, W. T. Lister, J. Herbert Parsons, G. Coats, A. C. Hudson, and R. A. Greeves.

The more recent volumes are fresh in the memories of readers, and their contents can be revived by a perusal of the general index published in this number. It is of interest to recall some of the earliest papers. The second volume is particularly interesting. There we read of night-blindness with scurvy in the Crimea, and on p. 42 it is stated that "in 1855 there were upwards of seventy cases of scurvy on the "Euryalus." "One of our staft is now serving on the "Euryalus" of to-day. There, too, we read William Mackenzie's observations on retinitis associated with renal disease, conical cornea by Bowman, with Hulke's microscopical examination, a note on persistent pupillary membrane by Wharton Jones, and so on. We can still learn a lesson from Streatfield's note on coloured papers, in which he describes how Babbage, the inventor of the ophthalmoscope, experimented to ascertain the best colour for the 
paper on which to print his logarithmic tables. The early volumes contain Soelberg Wells's papers on paralytic affections of the muscles of the eye, and Jonathan Hutchinson's on syphilitic inflammations of the eye. Here, too, are Hughlings Jackson's papers on defects of sight in diseases of the nervous system. In vols. iii and iv he finds chiefly optic atrophy; in vol. iv he distinguishes between nerve atrophy (primary) and cerebral atrophy (post-neuritic); in vol. viii he publishes two cases, one of cerebral tumour without optic neuritis, and another of double optic neuritis without cerebral tumour.

And so we may bid farewell. The familiar brown-covered parts will no longer be seen. The spirit which gave them birth sometimes flagged, but never died. It is not dead now, but re-kindled into a newer and livelier flame. Le roi est mort! Vive le roi!"

\section{The War Activities of an Ophthalmological Society}

An interesting account of the work accomplished by the Ophthalmological Society of Paris during the war is given by Rochon Duvigneaud in the Annales d'Oculistique of July last.

The Society has been by no means idle in the period under review. In October, 1914, it addressed a letter to the authorities asking for a better distribution of wounded soldiers in the special hospitals of Paris, and furnished the necessary information dealing with this subject. A second letter was sent to the Minister of War, advocating the advantages of introducing cylindrical lenses into the optical correction allowed to soldiers : shortly afterwards a ministerial decision was promulgated to the effect that astigmatism was compatible with service in the field when the visual defect was adequately compensated by cylindrical glasses. In 1916 the Society recommenced its regular meetings, compensating the absence of such of its members as had been mobilized by the admission to its meetings of ophthalmologists, native and allied, who were stationed in Paris, as Bourgeois, Moreau, Genet, Roy (Canadian Army), Quentin, Coulomb, etc.

In April and July, 1916, and in May, 1917, the Society devoted three meetings to the discussion of war subjects. The importance of these meetings was recognized by the authorities, as shown by the fact that they were presided over by M. Justin Godart, the Under Secretary of State of the Military Sanitary Service, who was accompanied by his medical staff. The Society is at present organizing another of these meetings, to be held during the ensuing winter. The participation of all mobilized ophthalmologists is invited. The titles of communications must be submitted, through the Society, to the Under Secretary of State, who will be asked to preside over the meeting. 